\title{
Entre la inspección y el cuidado. La mirada sobre los cuerpos en los programas de afectividad y sexualidad en Costa Rica
}

\section{Between inspection and care. The look on the bodies in the programs of affectivity and sexuality in Costa Rica}

\author{
Daniel Vindas Sánchez \\ Universidad Nacional de Costa Rica
}

\begin{abstract}
Resumen
El presente artículo se propone hacer un análisis teológico y filosófico de los Programas de Afectividad y Sexualidad del Ministerio de Educación Pública Costarricense. En primer lugar, busca comprender el asidero arcaico que influye esta forma de ética sexual, a través de la figura del pedagogo, el abad y el médico. Una de las hipótesis centrales de este trabajo es que estos Programas en gran parte participan de una regla sin monasterio, dentro de un esquema ético que está entre la inspección y el cuidado de sí, de manera que el análisis de estas guías supone de primera entrada, una paradoja.
\end{abstract}

Palabras clave: Cuidado de sí, inspección, cuerpo, sexualidad

\begin{abstract}
This paper intends a theological and philosophical analysis of the Affective and Sexuality Programs of the Ministry of Costa Rican Public Education. First, it seeks to understand the archaic grip that influences this form of sexual ethics, through the figure of the pedagogue, the abbot and the doctor. One of the central hypotheses of this work is that these Programs largely participate in a rule without a monastery, within an ethical scheme that resides between inspection and self-care, a paradox that has to be confronted in these guides.
\end{abstract}

Keywords: Self-care, Inspection, Body, sexuality 


\section{Introducción: El habitus del pedagogo como maestro de vida}

Las políticas contemporáneas de inspección sobre los cuerpos tienen un trasfondo ya sea filosófico o teológico. Lo anterior se puede inferir sobre todo por la premisa de que existe una ética que se nos presenta desde diferentes lugares o posicionamientos de interpretación en torno a las pasiones, de aquí que comprenderse a sí mismo sigue siendo una de las máximas del género homínido, trayendo junto a esta faena otro desafío crucial, el de cuidarse a sí mismo. Para llevar a cabo esta faena, la cultura antigua no solo se sirvió de la filosofía y la teología, sino de la medicina. Ya en el siglo II de nuestra era el compendio para ejercer una ética sobre las pasiones incluía a los médicos naturalistas desde Hipócrates hasta Galenoํㅜㄹ

1 En Galeno (140-199 d.C), por ejemplo, se encuentra el más vivo ejemplo del médico que es también filósofo y que incluye dentro de su corpus toda una ética de la salud. Si bien, algunas de las posturas de Galeno ya no se sostienen, sirven de asidero arcaico para comprender como se integraban ampliamente aquellos dos saberes, la filosofía y la medicina, de la cual se sirve después la misma teología. En Galeno ya se encuentra una teoría temprana de la naturaleza de los sexos donde existía el postulado de que el hombre lograba guardar más calor desde la matriz, de ahí el calor de su semen o semilla (semine) la mujer en cambio, no lograba guardar o recoger ese calor materno y por ello su condición corporal es más fría según el médico antiguo, esto posibilitaba la interpretación de que la mujer albergaba un vientre fresco y húmedo para la concepción. "Como proponía Galeno en su tratado Sobre la semilla, la falta de calor desde la infancia puede hacer que el cuerpo del varón recaiga en el estado de indiferenciación originaria. Ningún hombre acompañado de interpretaciones de las Sagradas Escrituras, así como el amplio corpus filosófico que iba desde Platón a Musonio Rufo.

El asidero filosófico corresponde a distintas técnicas de sí influenciadas por escuelas filosóficas como el platonismo, el estoicismo, y de manera más arcaica la escuela socrática; si bien estas escuelas de pensamiento no ejercían estrictamente una regla monacal como la que veremos en Benito de Nursia (480-547), tenían un régimen sobre el cuerpo, destinado al cuidado. Estas escuelas filosóficas, cada vez más inclinadas a estos ejercicios de ética llegaron hasta el pensamiento cristiano, específicamente dentro de la obra de Clemente de Alejandría (150-211). El habitus, antes de ser vestimenta, se ejercía como un modo de ser o de habitar la propia casa, es decir, una forma de gobernar las pasiones del cuerpo. Así pues, habitus implica unos ejercicios de ética que son traspasados algunas veces por el fervor religioso.

Si bien, en este trabajo se pretende comprender esa figura del pedagogo

normal podía convertirse realmente en mujer; pero todo hombre temblaba al verse a punto de volverse "afeminado". Su frágil calor era una fuerza incierta. Para que se conservara eficaz, había que mantener conscientemente su impulso. Nunca era suficiente con ser varón: un hombre tenía que esforzarse para mantenerse "viril". Tenía que aprender a excluir de su carácter y de su porte y temple corporales todos los rasgos evidentes de la "blandura", que delataran que estaba sufriendo una transformación femenina" (Brown 1993, 28-9). 
atravesada por influencias tanto cristianas como filosóficas, también surge la figura del abad como continuación de aquel maestro de vida. No significa que ambas figuras sean idénticas, pero sí es oportuno analizar tanto sus cercanías como sus diferencias. El primer paso para realizar este estudio radica en la problematización de los placeres y los afectos que está palpable en los programas de afectividad en la educación costarricense, el cual nos lleva a cuestionar y comprender si en la inspección exhaustiva existe un verdadero cuidado de sí. Estas figuras, la del pedagogo, la del abad, inclusive traspasadas por la del médico, servirán para analizar los elementos éticos que rodean la comprensión moderna y contemporánea de la sexualidad.

Si nos remontamos a la antigüedad clásica, podemos remitirnos a los requerimientos socráticos en torno a las pasiones, donde aquella idea de sophrosyne (mesura) era el sinónimo de la virtud ${ }^{2}$ más noble. Esta noción socrática de sophrosyne no era una prohibición, ni un tabú, mucho menos un precepto moral de inspeccionar el cuerpo bajo la impronta de la culpa, el pecado o la salvación. No será necesario detenerse acá en los ejemplos más concretos, basta

2 "La consideración de la virtud como bien máximo, como valor y criterio supremo para nuestras decisiones, no es en Sócrates una forma de rigorismo ascético desentendido de la felicidad. La ética socrática no es una ética de deberes. Sócrates conecta virtud con felicidad" (Calvo Martínez 2013, 123). con consultar los diálogos platónicos ${ }^{3}$, donde la polifonía de tonalidades filosóficas se vuelve siempre hacia las pasiones humanas.

La ocupación de sí en la manifestación de los afectos es un tema que atraviesa la condición humana en su dimensión educativa, es por eso que resulta pertinente atender, analizar y comprender la relación recurrente que existe entre las prácticas pedagógicas y el cuidado de sí. En la Antigüedad clásica y tardía, ser un paidagogos implicaba guiar a su discente hacia una vivencia saludable de los afectos, es decir, existía una tarea cotidiana ahí donde el maestro del Liceo (didaskalos) no podía llegar. El paidagogos lograba trascender inclusive las barreras de los estamentos sociales, pues muchas

3 En el Timeo por ejemplo, una de las máximas es comprender la armonía existente entre el alma y el cuerpo, el cultivo del cuidado de sí como acto que se ejerce para moderar las pasiones, así como la importancia del movimiento físico del cuerpo. En el Fedón se encuentra una exposición amplia sobre el alma, en una suerte de tratado que asocia al alma con las pasiones más profundas del ser humano, que van desde lo más racional, hasta lo más irascible e intemperante. En El Banquete, por ejemplo, es una figura femenina la que cierra un simposio a cargo de hombres, dando así lecciones sobre el significado de Eros al mismo Sócrates. Para este cometido se pueden consultar las mismas obras de la Biblioteca Clásica Gredos: Platón. El Timeo. Diálogos VI. Filebo, Timeo, Critias. Traducción, introducción y notas por María Ángeles Durán y Francisco Lisi. Madrid: Gredos, 2014. También Platón. Diálogos III. Fedón, Banquete, Fedro. Traducciones, introducciones y notas por C. García Gual, M. Martínez, Hernández, E. Lledó Íñigo. Madrid: Gredos, 2008. 
veces un esclavo (doulos) era asimismo pedagogo también.

Consideramos que la pedagogía es la conducción de los niños a la virtud, reza Clemente de Alejandría en el libro I de su obra El Pedagogo. En este mismo libro enseña que el pedagogo es un curador de pasiones, siendo a un tiempo maestro, filósofo, médico y guía espiritual, una figura que para Clemente solo es encarnada de manera virtuosa en la persona de "Cristo. El Pedagogo es educador, no experto, no teórico; su objetivo es la mejora del alma, no la enseñanza, como guía que es de una vida virtuosa, no erudita" ${ }^{4}$. Hay un pasaje gracioso en el Pedagogo en el cual Clemente crítica a las mujeres porque abren mucho la boca para beber, eruptan como los hombres o peor como los esclavos, además se dedican a una vida voluptuosa, nada más ajeno a la virtud que pretendía aquel filósofo cristiano ${ }^{5}$.

Esta es una figura que requiere una atención mesurada y analítica, pues no se debe pasar por alto, la imbricación cristiana de una figura que en un momento era más filosófica y que devino en una figura también espiritual. A partir de esta premisa, surge un primer tópico que a su vez es un cuestionamiento en la comprensión de las políticas

4 Clemente de Alejandría, El pedagogo (Madrid: Gredos, 1998), I, 4. Traducción de Joan Sariol Díaz, 42.

5 Clemente de Alejandría, El pedagogo... II. Traducción de Joan Sariol Díaz, 172. de los afectos, y radica en plantearse si es posible una figura que haga de paidagogos ahí donde el terreno no es estrictamente cotidiano si no académico. Lo que supone una paradoja, lejos de ofrecernos distancias, nos insinúa las más íntimas cercanías, es decir el mundo de la casa y la socialización primaria familiar frente al mundo escolar, son dos espacios sociales que en la Antigüedad no tenían una estricta separación para la figura del pedagogo, pues el discente que acudía a la academia con el didaskalos era aquel mismo que recibía la recta educación del pedagogo.

Otro referente, pero filosófico, es la obra de la Éthica o Moralia de Plutarco (46-120 d.C.), en la cual de manera erudita a lo largo de catorce manuscritos, aquel pensador moralista instruía a la juventud. En su versión latina Obras Morales y Costumbres escrita entre el 90 y el 117 d.C., encontramos un referente para comprender ampliamente esta figura del maestro de vida. Si comparamos la Moralia con la Regla de San Benito por ejemplo, podremos hallar curiosas similitudes así como algunas distancias en torno a demandas específicas sobre el cuerpo. Dentro de la obra de Plutarco encontramos tópicos que sirven de terreno fundante para la historia de la pedagogía occidental, dando una especial atención al tema del silencio, pero no como el arte de hacer callar, sino el de saber escuchar, asimismo el valor fraterno de la amistad, así 
como la elección de parte de los padres de un pedagogo de buenas costumbres ${ }^{6}$, y la negativa a cometer castigos físicos en el ejercicio de la educación, algo que sin duda llama mucho la atención en la obra del filósofo griego, seguidor además, de la armonía platónica entre al alma y el cuerpo.

Para Plutarco, el dominio total de las pasiones es cosa de dioses, dejando para los humanos una ética que busca la perfección, también platónica, en el ejercicio del gobierno de sí mismo, claro está, esta ética no llegará a consumar del todo aquella perfección, sino que se muestra a sí misma como camino pedagógico para el ejercicio del cuidado de sí. Este ejercicio del cuidado se observa en la pedagogía contemporánea por su influencia arcaica en el amor por lo que se conocía como las enkyklios paideia ${ }^{7}$ o las artes liberales, que buscan aquella armonía entre la parte física a través del deporte, la lúdica con la música o la poesía, y las demás ciencias en el ejercicio de la razón y el buen comportamiento, dentro de las cuales la filosofía estaba a la cabeza.

6 Plutarco. Obras morales y de costumbres, Moralia I (Madrid: Gredos, Biblioteca clásica 78 y 213 , 1995), I, 1. Traducción Concepción Morales y José García López, 54-5: "Se debe buscar para los hijos unos maestros que sean irreprochables por su género de vida, irreprensibles en sus costumbres y los mejores de su experiencia, pues la fuente y raíz de una conducta intachable es casualmente una buena educación".

7 Plutarco, Obras morales y de costumbres..., I,1. Traducción Concepción Morales y José García López, 62.
De manera que, el filósofo era una figura cercana al pedagogo por su carácter vivencial en el mundo de la pedagogía, llegando a ser comparado con un médico ${ }^{8}$. Toda esta influencia llegará a la obra de Clemente, como veremos, asimismo a las reglas de vida monásticas, de las cuáles bebe la educación contemporánea, dentro de esta paradoja que hemos denominado entre la inspección y el cuidado. Con el aspecto monacal de la educación, aquellos ejercicios de ética se convirtieron en Regula, inclusive regla sin monasterio. Cabría preguntarse, de qué manera aquellos ejercicios de ética helénicos se fundieron con la regla monacal como una forma de llevar aquel examen de sí a la radicalidad, pasando de la educación sin castigo de un Plutarco a la regla punitiva del claustro. Sin duda, que la cercanía entre la pedagogía clásica y las reglas monásticas está en las técnicas de comprensión de sí mismo, de un examen de sí y de un cuidado estricto, sin embargo, las distancias están en un creciente elemento punitivo que podemos encontrar ya en Benito

8 Plutarco, Obras morales y de costumbres..., I, l. Traducción Concepción Morales y José García López, 63. La filosofía como remedio para los males del alma, y el filósofo como médico del alma aparecen con frecuencia en la literatura del helenismo y en los estoicos tardíos, como Séneca y Marco Aurelio.

9 Plutarco, Obras morales y de costumbres..., I, 1. Traducción Concepción Morales y José García López, 66: "Yo afirmo que es necesario que los niños sean conducidos hacia los buenos hábitos con consejos y razonamientos, pero no, por Zeus, con golpes y ultrajes". 
de Nursia y su regla, donde se observa más pronunciadamente el castigo físico, la excomulgación, las penitencias, hasta la expulsión o exilio definitivo del monasterio.

\section{Teología de la vestimenta: Crítica del habitus monacal como ejercicio pedagógico}

En efecto, era el paidagogos la figura más íntima en el ambiente afectivo del aprendiz, pues vigilaba como estricto preceptor todo lo referido a sus afectos, pasiones y conductas, inclusive en la comida, la bebida y el vestido. Imposible no recordar al subdirector del Liceo donde estudié, quien constantemente vigilaba que mis faldas se acomodaran matemáticamente dentro de mi pantalón, que no usara aquellas tenis o calzado informal, mucho menos usar el cabello medio largo como lo usaba y muy importante, lo que hoy llamamos la faja o el cinturón; no sabía en aquellos años, del aspecto clerical que podía tener algo como el cinturón, lo cierto es que en estos bellos recuerdos de colegio puedo comprender unos años después aquel carácter monacal del director del Liceo representativo de la educación costarricense, nuevamente, regla sin monasterio.

Aquella teología de la vestimenta aún presente en esta regla sin monasterio, tal y como lo expresé en el anterior ejemplo biográfico, ha sido minuciosamente pensada para ejercer esa vigilancia corporal. San Benito, insistía en que los monjes debían dormir con ropa por ejemplo, con el cinturón bien ajustado. Ya en la primera sección del habitum monachorum de las Instituciones cenobíticas de Casiano se comenzó a instaurar paso a paso el uso de la capucha para representar la inocencia del niño, de la manga corta en señal de renuncia -porque la manga larga era señal de elegancia- también la mantilla o túnica que envuelve el cuello y los hombros en señal de humildad, los tirantes que simbolizan la laboriosidad del trabajo manual, el báculus o bastón para caminar en Cristo, las sandalias y el cinturón que convertían al monje en un soldado de Cristo listo para combatir al demonio y, asimismo, como decía Casiano para la mortificación de los miembros en los que son contenidas las semillas de la lujuria y la libídine ${ }^{10}$.

El hábito monacal ${ }^{11}$ nace como una encarnación, si se quiere extensión del cuerpo. Este habitus existe inclusive antes

10 Giorgio Agamben. Altísima Pobreza. Reglas monásticas y forma de vida. Homo Sacer IV, I. Traducción de Flavia Costa y María Teresa D’Meza. (Valencia: Pre-textos, 2014), 32-33.

11 En el siglo IV se podrían distinguir cuatro tipos de monjes, comenzando por los anacoretas o ermitaños, siguiendo con los cenobíticos o los que practican la vida común del monasterio, luego los sarabaítas, famosos por sus vidas licenciosas y desordenadas, terminando con los giróvagos, quienes siendo ya conocidos por la gula y el mismo desorden que practicaban los sarabaítas, eran dados a viajar de un lado a otro, aumentando de esa manera su mala fama. 
de la vida monacal ${ }^{12}$, pues este hábito es una ética, de habitarse a sí mismo. Uno de los desafíos de la educación contemporánea es comprender cómo este habitus se convirtió en regla. A las alturas del siglo V d.C. el hábito como vestimenta no logra distinguir aún la vida monacal de la secular. Al monje le distinguía su estricto régimen y no fue hasta el Concilio de Mâcon en 581 d.C. que se logró una especial distinción entre hábito religioso y hábito secular, era necesario extender en la vestimenta un símbolo fiel del sosiego del cuerpo y sus pasiones. El hábito es el primer uniforme-símbolo en la historia religiosa de la humanidad, no porque se omita la existencia de otros como el púrpura del rey, o el pallium negro del filósofo antiguo, sino porque este logra sintetizar el compromiso de llevar un cenobio ya institucionalizado que, si bien existía antes del monasterio, ahora habitar es un ethos que indica también formas de convivir, de ser y de sentir, y desde luego de vestir.

12 Colombás García M., El monacato primitivo (Madrid: BAC, 2004). El monacato como vida anacoreta o de corte ermitaño se remonta desde antes del siglo $\mathrm{V}$ a.C, en el hinduismo, y posteriormente el jainismo y budismo. Un dato particular es que para estas corrientes ascéticas se puede prescindir de la divinidad en el ejercicio ascético, tal es el caso del budismo. "La India lo ha comprendido tan bien que, según sus tradiciones canónicas, dos de las etapas que debería recorrer todo hombre en el camino de su vida son de tipo ascético o monástico: durante su juventud, como estudiante célibe, debe aplicarse a aprender las tradiciones védicas bajo la instrucción de un guru (maestro) luego debe casarse, engendrar hijos y contribuir para el bienestar de la sociedad" (12-3).
Existe a partir del hábito, toda una teología de la vestimenta. El hábito es performativo, convierte al monje en una suerte de actor, es una suerte de disfraz del aprendiz de santo. El hábito es la nueva máscara pues porta consigo un fin apotropaico (que aleja el mal). Pero habitus en tanto modo de ser, como sucedía antes del monasterio, existía como regla de vida, en la figura del pedagogo y su discente, ya desde el tiempo de la escuela estoica de Séneca, existía una asociación de la vida ermitaña con la sabiduría. El filósofo griego, por ejemplo, recomendaba alejarse de la multitud ${ }^{13}$. Con el tiempo, la vida ermitaña ${ }^{14}$ se convirtió en regla, inclusive como requisito para convivir dentro del cenobio, hasta que esta regla se invirtió a tal punto que

13 Séneca. Epístolas Morales a Lucilio I (Madrid: Gredos, 1986), Libro I, Epístola 7. Traducción de Ismael Roca Meliá, 113. Uno de los argumentos que da Séneca para detestar a la multitud son los espectáculos de gladiadores, que reúnen a la multitud, para ver como aquellos luchadores se matan entre ellos por el placer de matar.

14 Las cartas de San Jerónimo representan un testimonio temprano del monacato occidental, inclusive anteriores a la Regula benedictina. La vida de Pablo el ermitaño o del mismo San Antonio en oriente, ya habían instituido este habitus orientado hacia la vida ermitaña como estricto régimen sobre las pasiones. A pesar de la renuncia al placer, el acto de la mortificación desértica era deliciosa para un San Jerónimo, quien escribía por ejemplo a Florentino lo siguiente: “...y yo estoy tan apartado en los confines del desierto que he escogido, que empieza a no serme lícito aquello a lo que he renunciado" A Florentino, 5, 2. En San Jerónimo. Obras Completas. Epístolas I. Edición bilingüe promovida por la orden de San Jerónimo. Introducciones, traducciones y notas por Juan Bautista Valero. (Madrid: BAC, 1993), 91. 
el cenobio era la norma ante la vida anacoreta. Se comprendía que la vida anacoreta era una forma de habitarse a sí mismo, convivir con las propias partes pudendas del cuerpo, examinarlas y estar atento ante todas las pasiones provocadas: el hambre, la sed, el deseo de la carne. Este es, pues, el habitus, una forma de habitar las pasiones en carne propia, ya en el desierto, ya en el monasterio, y en el propio cuerpo social en el que habitamos. Por consiguiente, este hábito lo portamos todas las personas, de alguna manera lo seguimos vistiendo a través de la educación que hemos recibido y que se sigue prolongando en nuevas generaciones, ya no reducido a algo como la vestimenta o la ropa, pero sí a un vestido simbólico que se relaciona con una pedagogía como modo de ser en la vida. En la vigilancia de medir los tiempos, las intensidades, los períodos en los que se consuma la sexualidad ya sea solo, ya sea acompañado, ahí en la intimidad del mismo aposento, ocurre este habitus, algunas veces como regla sin monasterio.

Dentro de los despliegues de este hábito de vida, existe un mecanismo importante, se trata de la confesión. En la Regla de San Benito aparece una obsesión por la confesión, al igual que en Clemente, pero a su vez por el silencio. Ambos extremos se funden ahí donde se le muestre humildad al superior a la hora de pedirle alguna cosa.
De nuevo, aparece el tema de la broma, aquel hombre linguaraz que se critica en Plutarco y Clemente, se consuma en la Regula benedictina: "Pero las chocarrerías, las palabras ociosas y las que provocan risa, las condenamos en todo lugar a reclusión perpetua. Y no consentimos que el discípulo abra su boca para semejantes expresiones" ${ }^{15}$. Más adelante, se verá como la máxima de hacer hablar, hacer callar, aún permanece en el régimen que ofrecen los programas de afectividad en Costa Rica, donde este se convierte en un mecanismo de confesión.

El filósofo italiano Giorgio Agamben, es un referente para desvelar el carácter profano de las reglas monásticas, es decir, permite escudriñar la disciplina monacal para comprender que es una suerte de red que amarra todo el cuerpo social, más allá del cenobio y del aposento monacal. En esta tesis de Agamben el koinos bios o vida común (cenobio) se extiende al mundo de la vida fáctica, dentro del cual se enmarca muy bien esta política pública de los Programas de Afectividad, se trata de una regla sin monasterio. Dentro de esta tesis se inscribe la idea de que estas guías sexuales ofrecen elementos clericales toda vez que buscan no solo inspeccionar cuerpos exhaustivamente, sino

15 Aranguren I, G.M. Colombás, La Regla de San Benito. Biblioteca de Autores Cristianos 406 (Madrid: BAC, 2006), Regula V, 7, 89. 
que pretenden extraer una verdad a través del dispositivo de la confesión.

Ahora bien, Agamben asevera que: "entre los siglos IV y V de la era cristiana se asiste al nacimiento de una particular literatura que, al menos a primera vista, no parece tener precedentes en el mundo clásico: las reglas monásticas"16. Partiendo del vínculo que existe entre la figura del pedagogo y la del abad por ejemplo, la tesis de Agamben puede percibirse como generalizada y criticable, pues con esta afirmación omite toda la literatura de los primeros tres siglos del cristianismo, de la cual ya hemos comentado acá, influenciada por el estoicismo, el platonismo y la escuela socrática, comenzando por la misma epistolografía paulina y en el caso concreto de Clemente de Alejandría en el mundo cristiano, pero también un ejemplo anterior a aquellos dos, el de Plutarco, el filósofo moralista, en el mundo pagano.

Tomando un distanciamiento con la tesis anterior de Agamben, podemos colegir que esta regla monacal refleja el minucioso y extenuante vigilar de los cuerpos, que alguna vez fue motivo de la ocupación de sí en aquella noción de Chresis aphrodision y que devino en Regula como estilo de vida preguntándose por todos los detalles, no solo sobre la carne, la comida o la bebida,

16 Giorgio Agamben, Altísima Pobreza (Valencia: Pre-textos, 2014), 17. sino en cuántos salmos han de cantarse en horas de la noche por ejemplo, cómo se han de celebrar los Laudes, a qué hora hay que decir Aleluya, como corregir monjes desobedientes, sobre todo si son jóvenes, cómo duermen, cómo visten, cómo calzan. Se incluye además el castigo físico cuando se da ya sea la desobediencia o la murmuración.

De aquellas reglas monásticas construidas ya por Casiano, Pacomio o Gregorio Nacianceno, el filósofo italiano afirma que "no son en suma hypomneumata o ejercicios de ética como los que Michel Foucault analizó en el mundo antiguo ${ }^{17 "}$, ante lo cual se sigue que es cierto lo que se comprende de aquellos ejercicios arcaicos destinados exclusivamente a la epimeleia o cuidado de sí, a la conservación de un cuerpo saludable y al buen uso de los placeres, sin embargo, la separación entre aquellos ejercicios de ética y el examen de sí llevado a la radicalidad de la vida monacal es problemática y supone una línea delgada, donde ambas, la primera arcaica, helénica y profana, así como la segunda, sacra, cenobítica y clerical, se encarnan en el más preciado fin de la ética sobre los placeres, es decir, el uso saludable del cuerpo y las pasiones. Tal separación, como la que hace Agamben, no permitiría ver con mayor amplitud, el régimen de vida saludable que existe en ambas vertientes citadas. Solo el

17 Giorgio Agamben, Altísima Pobreza..., 18. 
caso de Clemente de Alejandría permite pensar ya una cristianización de aquel régimen de vida, una regla que ya no es pagana pero que tampoco es cristiana al estilo monacal, una regla si se quiere, casi idéntica al cultivo de la aphrodisia helénica, con un mismo fin, el hecho de perpetuar la especie a través del matrimonio, encontramos ese mismo régimen, sin modificaciones esenciales, en la doctrina de los Padres del siglo II $^{18}$.

La figura del abad tiene un vínculo significativo con la del pedagogo, aunque este último es menos sacro, tiene la tutoría de un conjunto de aprendices en torno a los manejos estrictos del habitar corporal. Casi al pie de la letra la Regula II de San Benito señala al abad como aquel que "reprende, exhorta, amonesta ${ }^{19}$ ", recordando las epístolas de San Jerónimo y la vida cenobítica inspirada al mejor estilo pacomiano del monacato egipcio. El abad, como el pedagogo, llama al sosiego pasional, más no a la estricta represión, un problema que le preocupara a la regla monástica será el de la desobediencia, o bien el de la murmuración, la risa y el multiloquio como acto de insensatez. Igual que las sentencias clementinas

18 Michel Foucault. Historia de la Sexualidad IV. Las confesiones de la carne. Edición establecida por Frédéric Gros, presentación de Edgardo Castro y traducción de Horacio Pons. (Madrid: Siglo XXI, 2019), 31.

19 Aranguren I, G.M. Colombás, La Regla de San Benito... Regula II, 23, 77. en torno a la risa, por ejemplo la Regula llama a permanecer prudentes para no reír con intemperancia ${ }^{20}$. Si se parte estrictamente del compendio clementino y su régimen de vida, es posible criticar el planteamiento de Agamben sobre las reglas monásticas como una literatura sin precedentes.

El reconocido historiador Jaques Le Goff, en su Historia del cuerpo en la Edad Media, recopila aquella tradición en torno a la risa que parte desde Platón y su aversión a los poetas, pasando por Clemente, la Regla del Maestro y desembocando en la Regla de San Benito, para Le Goff esta tradición se extiende inclusive hasta el siglo XII. La línea argumentativa en términos generales estriba en que la risa proviene de una parte baja del ser, es decir del vientre, provocando así un movimiento que puede descender y provocar el alboroto de las partes pudendas, según la creencia de la época, por la risa entraba no solo el pecado, sino la intemperancia y el descontrol de las pasiones: "la risa camina desde las partes bajas del cuerpo, pasando del pecho a la boca. De esta última, tanto pueden salir palabras de devoción, de piedad, y de plegaria, como palabras procaces y blasfematorias" ${ }^{21}$.

20 Aranguren I, G.M. Colombás, La Regla de San Benito..., Regula, IV, 52, 53 y 54, 84.

21 Jaques Le Goff y Nicolas Truong. Una historia del cuerpo en la Edad Media. (Barcelona: Paidos, 2005), 65. 
El llamado a la rectitud es minucioso en la Regla benedictina, a tal punto de llevar una estricta vigilancia sobre el accionar de los cuerpos de los jóvenes monjes, el abad hará también de confesor ${ }^{22}$, quizá una de las figuras más arcaicas de lo que más adelante en la Edad Media será el manual de confesión y el confesionario como dispositivo de extracción de verdad. En el monasterio pensado por San Benito, existe un colaborador nocturno en la figura del anciano, que vigila cuerpo a cuerpo, cuarto a cuarto, que ningún joven se encuentre con otro para algún acto carnal ilícito, vigilará además que guarden silencio, que resista injurias ${ }^{23}$, que no sea airoso y que practique la parquedad de la palabra ${ }^{24}$, aunado a un sosiego relacionado a la risa ${ }^{25}$, el silencio es lo que debe imperar antes de dormir. Una lámpara acompañará el aposento de cada grupo de monjes ${ }^{26}$, cual si fuese la luz tenue de una temprana conciencia materializada en Dios ante la impronta

22 Aranguren I, G.M. Colombás, La Regla de San Benito..., Regula, VII, 44, 96.

23 Aranguren I, G.M. Colombás, La Regla de San Benito..., Regula, VII, 35, 95.

24 Aranguren I, G.M. Colombás, La Regla de San Benito..., Regula, VII, 56, 98.

25 Aranguren I, G.M. Colombás, La Regla de San Benito..., Regula, VIII, 59, "El décimo grado de humildad es que el monje no se ría fácilmente y en seguida, porque está escrito: el necio se ríe estrepitosamente". Llama la atención está última frase que San Benito toma de El Enchiridion de Sexto Empírico dejando ver la influencia filosófica de la antigüedad tardía en la regla de vida cristiana.

26 Aranguren I, G.M. Colombás, La Regla de San Benito..., Regula, XXII, 4, 116. de la figura naciente del diablo. Igual que el pedagogo clementino, el abad y su colega el anciano son comparados con un médico, que portan el antídoto de la temperancia cristiana y quien no cumpla con las reglas no solo será excomulgado o castigado, sino que será echado del monasterio hasta tres veces.

Aún en la vivencia del cenobio, o con más razón gracias al mismo régimen, la capacidad lúdica o trasgresora del ser humano sale a relucir, tal es el caso de los monjes sarabaítas, quienes se tomaron en serio la máxima presente ya en Casiano, ya en Agustín: Ama y haz lo que quieras. Sírvase la misma regla de San Benito para describirlos:

El tercer género de monjes y pésimo por cierto, es el de los sarabaitas. Estos se caracterizan, según nos lo enseña la experiencia, por no haber sido probados, como el oro en el crisol, por regla alguna, pues, al contrario, se han quedado blandos como el plomo. Dada su manera de proceder, siguen todavía fieles al espíritu del mundo, y manifiestan claramente que con su tonsura están mintiendo a Dios. Se agrupan de dos en dos o de tres en tres, y a veces viven solos, encerrándose sin pastor no en los apriscos del Señor, sino en los propios, porque toda su ley se reduce a satisfacer sus deseos. Cuanto ellos piensan o deciden, lo creen santo, y aquello que no les agrada, lo consideran ilícito ${ }^{27}$.

27 Aranguren I, G.M. Colombás, La Regla de San Benito..., Regula I, 6-9, 72-3. 
Para aquellos monjes la regla era más bien una parodia del monasterio basada en el capricho y el deseo ${ }^{28}$. Y dentro del cuarto género de monjes, similar a los anteriores, encontramos a los giróvagos quienes se la pasan viajando su vida entera por diversos países, hospedándose durante tres o cuatro días en los monasterios. Siempre errantes y nunca estables, se limitan a sus propias voluntades y a los deleites de la gula; son peores en todo que los sarabaítas ${ }^{29}$. Si se siguen las tesis de Agamben, es posible encontrar en la vida misma una forma de Regula, como ya hemos dicho, sin monasterio, donde el hábito como tal se extiende, al parecer sin escapatoria, a todos los rincones del tiempo, del espacio y del cuerpo. Dentro de este esquema de régimen de vida están enmarcados los programas de afectividad como una forma de producir políticas sobre el cuerpo, de alguna manera regladas, en busca de diferentes objetivos, en el mejor de los casos, una sexualidad saludable.

\section{Habitarse a sí mismo: la} paradoja de la educación entre la inspección y el cuidado

Es posible encontrar ya en Clemente, ya en San Benito, influencias filosóficas en la formación de dos figuras antiguas, la del estudiante de filosofía y su manejo cotidiano de los afectos

28 Giorgio Agamben, Altísima Pobreza..., 22.

29 Aranguren I, G.M. Colombás, La Regla de San Benito..., Regula I, 10-11, 73-4. y pasiones, así como la del novicio, quien hace también de discente, pero en un plano más monástico. Es sabido que en el siglo XXI no habría distinción civil entre uno y otro, es decir, tanto el colegial como el novicio encarnan la figura del ciudadano, pero en términos más profundos el de persona humana. Existe un trasfondo clerical en el modelo de educación costarricense y estos programas en parte lo reproducen, en parte lo critican. Al otro lado está, la figura del pedagogo, entre la del abad y el médico.

Una forma de comprender este fenómeno a la perfección está en la figura de los centros educativos religiosos, llámese colegio Claretiano, Redentorista, de Señoritas, María Auxiliadora, entre otros, en la cual se mantiene el abordaje religioso cristiano en el aprendizaje de las personas discentes, es decir, a pesar de que la persona estudiante no es un novicio recibe una formación cercana, o en el caso de las damas la educación de una monja, desde luego impartida por alguna madre superiora o abadesa. Claro está, un análisis exclusivo de estos centros de estudio confesionales no representa la diversidad de centros de estudio en los cuales la educación pretende ser más laical.

Por ejemplo, resulta curioso observar los cuestionamientos dentro de los diseños curriculares y constatar ahí similitudes con las inquietudes sobre sí 
mismo que plantean los textos antiguos supracitados. Observemos que, dentro de la Ethica, Plutarco se plantea temáticas y preguntas como las siguientes: sobre la educación de los hijos, cómo debe el joven escuchar poesía, cómo distinguir a un adulador de un amigo, cómo percibir los propios ingresos en la virtud, cómo sacar provecho de los enemigos, sobre la virtud y el vicio, consejos para conservar la salud, asimismo un tratado llamado Erótico y otro sobre Narraciones de amor ${ }^{30}$.

En el Erótico se da una disputa sobre el amor conyugal entre hombre y mujer defendido por Plutarco, algo que enoja mucha a Pisias y a Protógenes quienes defendían la antigua relación entre el erastes (el amante adulto), y el eromenos (el amante joven), ambos varones, y donde la barba tenía un aspecto medular. Este tipo de relación llamada en aquella época pederastia, no fue vista con buenos ojos por algunos filósofos estoicos quienes llegaron a influenciar el pensamiento paulino y el del mismo Clemente. En boca de Flaviano, uno de los interlocutores del diálogo, se ofrece la siguiente definición del amor: Como la naturaleza

30 Plutarco. Obras Morales y de Costumbres. Volumen X. Erótico, Narraciones de amor, Sobre la necesidad de que el filósofo converse con los gobernantes, A un gobernante falto de instrucción, Sobre sí el anciano debe intervenir en política, Consejos políticos, Sobre la monarquía, la democracia y la oligarquía, La inconveniencia de contraer deudas. Vida de los Diez oradores, Comparación de Aristóteles y Menandro (Madrid: Gredos, 2003). despierta un apetito moderado y suficiente por el pan y los alimentos, más el exceso convertido en pasión se llama glotonería y gula, de igual modo está en la naturaleza la necesidad del mutuo placer entre mujeres y hombres, más el impulso que a ello mueve, cuando por su fuerza y vehemencia se hace violento e incontenible, indebidamente lo llaman Amor ${ }^{31}$.

Observemos ahora, los cuestionamientos ofrecidos en una de las unidades de estudio para jóvenes de sétimo año:

¿a qué edad debe tener la primera menstruación una mujer? ¿cuál es el peso ideal de un adolescente hombre? ¿Cuál es el peso ideal de una adolescente mujer? iA qué edad se debe dar el primer beso? ¿A qué edad se debe tener la primera relación de pareja? ¿Cuántos/as mejores/as amigos/as se puede tener? ¿Cuántas veces a la semana debería salir un/a adolescente a solas con ser/madre? ¿Cuál es la estatura ideal de un hombre adolescente? ¿Cuál es la estatura ideal de una mujer adolescente? ¿A qué edad se autoestimula genitalmente por primera vez un hombre? ¿a qué edad debe autoestimularse genitalmente por primera vez una mujer ${ }^{32}$

Estos cuestionamientos obedecen a categorías analíticas ofrecidas dentro del programa en las cuales figuran la

31 Plutarco, Obras morales y de costumbres X..., 47.

32 Ministerio de Educación Pública, República de Costa Rica. Programa de Estudio de Afectividad y Sexualidad. Tercer ciclo. (San José: MEP, 2017), 9. 
nociones de cuerpos y corporalidades, afectos y vínculos, placer y bienestar y derechos sexuales y reproductivos ${ }^{33}$, por ejemplo.

Podemos inferir en estos cuestionamientos una obsesión por la relación cuerpo-tiempo, y cabe preguntarse si en esta inspección exhaustiva existe realmente una ética del cuidado de sí, poco falta para preguntar a la juventud cuántas veces respira al día. Se observa una insistencia en aspectos cuantitativos: cuánto peso, cuántos amigos, cuánta edad para masturbarse, cuál edad para tener novio o novia, casi al mejor estilo de la inspección del niño masturbador ${ }^{34} \mathrm{o}$ las minuciosidades de la Regula benedictina. Por consiguiente, queda una vez más sobre la mesa este cuestionamiento, si en la confesión e inspección de estos cuerpos existe realmente una ética del cuidado de sí, o una mirada casi médica y cansante sobre aspectos y mínimos detalles sobre las formas de expresar afectos.

En la Antigüedad tardía el pedagogo y el abad eran comparados con los médicos, pero en la modernidad este rol se invierte, dándole al médico un

33 Ministerio de Educación Pública, 28-9.

34 Alain Corbin, Jean-Jaques Courtine, Georges Vigarello. Historia del cuerpo. Volumen III. Las mutaciones de la mirada: El siglo XX. Traducción de Alicia Martorell y Mónica Rubio. (Madrid: Taurus, 2006), 111. "La masturbación aparece como universal para los chicos a partir de los once o doce años y Kinsey subraya que no tiene ningún efecto perjudicial para la salud". papel sacro dentro de lo profano, en el sentido que vigila como antes lo hacía el monje o el pedagogo, da instrucciones sobre el cuerpo y hace de curador de todas las pasiones, los males y las enfermedades, sutura el cuerpo, lo mutila si es necesario, el médico ejerce sobre el cuerpo roles que lo llevan a la radicalidad. Será el médico, inclusive, quien determine el sexo del neonato, en las sociedades modernas el médico hace de abad en tanto que se convierte en un nuevo bautizador. Por consiguiente, debe llamarse la atención, en torno a estos programas y preguntarse si no se trata más bien de un manual de producción de cansancio, y no un acompañamiento más genuino, placentero y libre en el ejercicio de las pasiones.

Hablar hasta el cansancio o callar hasta el cansancio casi al estilo benedictino, se observa concretamente en una de las situaciones didácticas en este caso en el segundo tomo, para estudiantes de décimo año. La temática es delicadísima y se valora el esfuerzo por darle un tratamiento serio al asunto, pues se trata de las personas que han sufrido acoso o abuso sexual. En esta situación, las personas estudiantes todas en silencio y con los ojos vendados ${ }^{35}$ acuden a la palabra de la persona docente, quien desde luego si podrá ver lo que las personas

35 Ministerio de Educación Pública, República de Costa Rica. Programa de Estudio de Afectividad y Sexualidad. Décimo año (San José: MEP, 2017), 43-4. 
estudiantes respondan con su cuerpo. Las preguntas son:

1) Que se pongan de pie aquellas personas que han vivido o conocen a alguien que ha vivido acoso callejero; 2) Que se pongan de pie aquellas personas que han vivido o conocen a alguien que ha sido mirada(o) o tratada de manera lasciva, vulgar e irrespetuosa en una perspectiva sexual; 3) Que se pongan de pie aquellas personas que han vivido o conocen a alguien que ha sido tocada(o) o manoseada(o) sin así quererlo por alguien más; 4) Que se pongan de pie aquellas personas que conocen a alguien que ha sido presionada a hacer algo de contenido sexual bajo amenaza de cualquier tipo; 5) Que se pongan de pie aquellas personas que conocen a una persona que ha sido abusada sexualmente por alguien en quien confiaba o a quien tenía miedo por su investidura o su poder y autoridad ${ }^{36}$.

Toda esta práctica de inspección hace hablar a los cuerpos sin por ello dejar de silenciarlos, las preguntas son indirectas, las personas en el limbo de los ojos vendados se levantarán tenuemente o quizá decididamente porque no se trata de ellos, sino como dicen las preguntas "si conocen a alguna persona" que ha sido manoseada, tocada o abusada sexualmente por una figura de autoridad. Lo criticable acá es, como en la Regula benedictina, la obsesión

36 Ministerio de Educación Pública, 43. por el silencio. En el silencio de palabra cada cuerpo del discente hablará seguramente. Lo de los ojos vendados, problemático, porque no hay una libertad más genuina de decir a viva voz, a viva mirada o a viva carne lo que realmente sucede en la vida de estas personas, sus relaciones conflictivas de amor y desamor, de violencia o de abuso. Se trata en este caso particular, de una situación didáctica con jóvenes de décimo año, con los cuáles se podría sostener una conversación más abierta, amena, cercana y madura, sin vendajes, donde hablen cuando deseen hablar y callen cuando deseen callar.

El problema no está en hablar, sino en hacer hablar, tampoco en callar, sino en hacer callar. La dinámica de hacer hablar, hacer callar siempre ha sido problemática, ningún imperativo ha dado resultado. Callar demasiado o hablar demasiado fue un punto importante en la pedagogía de Plutarco, pues: "Yo sé, por haberlo oído, que muchísimos hombres cayeron en las mayores desgracias a causa de la incontinencia de su lengua ${ }^{37 "}$. En la pedagogía de Plutarco permanece la mesura platónica de hablar lo necesario, dar la palabra al discente siempre será una forma de hacerle libre. Por lo tanto, es oportuno preguntarse no solo si de le da la palabra a la persona discente sino

37 Plutarco, Obras morales y de costumbres I, 1. Traducción de Concepción Morales y José García López, 72. 
de qué forma esta palabra tiene un fin económico, liberador y saludable.

La reflexión anterior nos lleva a un siguiente cuestionamiento, sobre la formación de las personas docentes en materia de género y sexualidad. Estas técnicas pedagógicas en torno a los afectos tienen como ejes centrales una educación repensada a partir de los derechos humanos, las diversidades, la interculturalidad, el género, la educación inclusiva, entre otros. La idea central es comprender estas técnicas y políticas sobre la afectividad y sexualidad, haciendo en primer lugar un análisis ético y filosófico de la figura de la persona docente, es decir, antes de ir a las prácticas educativas, hay que comprender históricamente el perfil académico, ético y porque no biográfico de la figura del maestro en su totalidad. En segundo lugar, ampliar la comprensión y las categorizaciones de las personas estudiantes según lo plantea el Programa de Afectividad y Sexualidad Integral en Costa Rica. A partir de la comprensión íntima que existe entre maestro y discente, se podrán ampliar las reflexiones hacia otros niveles, es decir hacia una comprensión más analítica, genealógica y desde luego ética de estas políticas afectivas.

Así pues, las políticas sobre la afectividad que ofrecen los programas de estudio de afectividad y sexualidad integral, nos invitan a repensar y releer la figura antigua del paidagogos, acompañada a la del didaskalos en torno a un fin común: la producción de identidades y subjetividades gratificantes. ¿Será posible ver en la figura del docente (didaskalos) un paidagogos? Es decir, se plantea la pregunta en primer lugar, sobre si el docente hasta cierto punto es un maestro y compañero de vida, a pesar de no vivir en la casa de la persona estudiante.

Claro está -y esta sería una primera objeción- no se puede fragmentar la casa y el centro de estudio, habida cuenta de sus relaciones íntimamente convergentes entre sí, pero así mismo conflictivas. Afectos que pululan en el secreto del hogar quizá no se manifiestan en el día a día del centro de estudio, o bien, situaciones afectivas y complejas que se viven en el ambiente colegial, solo se desahogan ahí donde el hogar se vuelve cárcel o espacio de disciplina. Por lo tanto, es el centro educativo aquel lugar que cuenta también como hogar para muchos, como cotidianidad y como espacio de expresión de afectos a veces reprimidos. En el encuentro con el colega de clase se crean lazos de hermandad que a veces el hogar no potencia. Es acá donde volvemos a la idea de la persona docente de clase como una figura que encarna a un tiempo al paidagogos y al didaskalos, ¿qué clase de figura es esta? Sin duda es parte de la discusión que acá nos reúne, conocer cómo es que una figura se 
encarna en la otra, y lejos de fragmentarse se encuentran, sin pasar por alto sus diferencias.

El Programa traza una serie de requerimientos y demandas dentro de las cuales encontramos las siguientes:

1. Es capaz de explicar el significado de conceptos clave como sexo, género, identidad de género, expresiones de género, orientaciones sexuales y diversidad sexual.

2. Conoce el origen, el contexto y el ejercicio de los Derechos Sexuales y Derechos Reproductivos, en el marco de un Estado de Derecho.

3. Reconoce los deberes y derechos de la ciudadanía, para garantizar la vivencia plena y placentera de la sexualidad de las personas y el desarrollo de las sociedades.

4. Está comprometido(a) con los valores de justicia, igualdad y respeto por la diversidad en la vivencia $y$ expresiones de la sexualidad.

5. Orienta la toma decisiones de sus estudiantes, para que favorezcan el autocuidado, el cuidado mutuo y la vivencia plena, placentera y responsable de la sexualidad como parte del bienestar integral de las personas.
6. Facilita los cambios en creencias y prácticas de sus estudiantes, a fin de reducir riesgos que puedan amenazar su salud sexual y su salud reproductiva, a partir de las condiciones individuales, sociales y ambientales.

7. Explica los factores y conductas de riesgo que podrían afectar la salud sexual y reproductiva de sus estudiantes, a fin de que éstos(as) se propongan cambios que refuercen sus conductas protectoras ${ }^{38}$.

Lo anterior nos permite inferir que, la persona docente deberá formarse primero antes de formar a las personas estudiantes. Deberá manejar claramente conceptos sobre teoría de género, masculinidades y feminidades, así como categorías basadas en la identidad sexual, diversidad sexual, entre otras. El papel de la persona docente será crucial y más crucial aún será su formación académica, en este sentido no solo será el paidagogos que acompaña y guía si no que debe encarnar al didaskalos que enseña con prestancia y maestría. Su formación debe ser integral. Finalmente, UNESCO (2010) señala las siguientes como las características de un programa efectivo de Educación para la Afectividad y Sexualidad Integral: "Involucra en el desarrollo curricular a personas investigadoras especializadas en sexualidad,

38 Programa de Estudio de Afectividad y Sexualidad. Tercer ciclo, 23. 
cambio conductual y teoría pedagógica relacionada con estos temas ${ }^{39}$ ".

En suma, dentro de los tópicos mencionados se plantea la inquietud de sí, es decir preguntarse cómo estas políticas de los afectos ejecutadas a través de esta figura pedagógica que está por definirse, contribuyen a construir y a repensar la noción de cuidado de sí mismo. Habrá que preguntarse si estas políticas sobre el cuerpo no caen también en normalizaciones, si pasan por alto detalles en la vivencia de los afectos que perciben como obvias o insignificantes, pero que puedan ser cruciales para quienes construyen su identidad, además si estas políticas presentes en los programas de afectividad y sexualidad son realmente gratificantes, si realmente se perciben como creativas y liberadoras para quienes van dirigidas; además preguntarse, cuál es el uso del tiempo con respecto al cuerpo y viceversa, si en medio de un programa de afectividad no se está cayendo en un programa de regulación disciplinaria del cuerpo que esté basada más bien en el cansancio.

\section{Conclusión: Hacia una pedagogía del cuidado en sociedades hipersexualizadas}

El Programa utiliza la noción de autocuidado, con la cual se entrará en diálogo en este trabajo. Es definido de la siguiente manera: "El autocuidado

39 Programas de Afectividad y sexualidad. Décimo año, 12. tiene que ver con las cosas que unalo hace, dice y siente para asegurarse y proteger la salud física, sexual, mental y espiritual propia ${ }^{40 "}$. No queda claro en esta definición a qué se refiere con cosas que uno hace sin embargo es una categoría, discurso y práctica que puede resultar gratificante en el marco de estos programas, que debería ampliarse e hilarse de manera más fina, recurriendo a la misma espiritualidad, a la visión de mundo y a la construcción de identidades de las mismas personas estudiantes. Algo que se puede criticar también es que, dentro de tantas preguntas, no aparecen preguntas hechas por personas estudiantes. En un salón de clase uno debería partir por las preguntas que las personas estudiantes tienen y que a menudo les inquietan.

Este trabajo se ofrece como un aporte a las prácticas pedagógicas tomando como referente teórico el análisis genealógico de las prácticas educativas encarnadas en los dos conceptos que hemos desarrollado en esta propuesta (paidagogos-didaskalos), las cuales encarnan la noción, aún prematura de maestro de vida. Claro está que, en el ejercicio de intercambio de saberes, una verdadera persona docente debe estar siempre con una actitud abierta para dejarse formar por su

40 La sexualidad y la salud sexual reproductiva de las y los adolescentes con énfasis en prevención de VIH/ Sida. Módulo de Capacitación para Adolescentes Multiplicadores en Salud (San José, Costa Rica, 2005), 91. 
discente, pues no se debe caer en una comprensión vertical de la pedagogía, sino en una relación cara a cara. De aquí que este trabajo se piensa como aporte crítico y, al mismo tiempo, a modo de comentario de las políticas de afectividad y sexualidad en la educación costarricense.

La noción de tratamiento o administración de la afectividad deberá trazarse e hilarse de manera más fina, sin embargo, se puede adelantar o apenas pergeñar la noción de políticas en tanto se enmarca en un programa pedagógico para un grueso importante de la población y que está dirigido a producir ciudadanos de la polis, en segundo lugar porque tiene un carácter gubernamental, no solo porque viene dirigida por una institución jerárquica que da pautas sobre cómo construirse subjetiva y socialmente, sino porque, en el sentido estricto de la palabra, el programa ofrece mecanismos para la práctica del gobierno de sí. Es acá, precisamente, a donde debe llegar la presente investigación, es decir sopesar analíticamente estás prácticas políticas del gobierno de sí mismo en los programas de afectividad, a saber, cuáles son sus alcances, sus limitaciones, sus aspiraciones emancipatorias, su aporte a la vivencia sana del cuerpo en el marco de los derechos humanos y la diversidad, así como su aporte a la vivencia de una sexualidad saludable.
Siguiendo con los sub-ejes encontramos el de placer y bienestar en el cual se afirma lo que podríamos denominar como hipótesis represiva, lo cual deja en la superficie un análisis más realista de las relaciones sexuales y de género. El texto dice:

(...) históricamente en nuestras culturas la sexualidad se ha asociado a lo prohibido, a lo reprimido y por lo tanto incluso muchos de los esfuerzos en educación de la sexualidad se han centrado únicamente en las consecuencias negativas de la vivencia de la sexualidad (ITS, embarazos no planeados, violencia, etc.). Por lo tanto, este saber pretende rescatar y legitimar los placeres de la vivencia de una sexualidad segura, informada y en corresponsabilidad; y cómo dicha vivencia garantiza bienestar y desarrollo para las personas, y por ende, para las familias, las comunidades y las sociedades en general. Los placeres y el bienestar que este saber aborda, se viven en el cuerpo pero también lo trascienden; no se segmentan ni parcializan las vivencias sino que se integran ${ }^{41}$.

Contrario a lo que se plantea acá, se puede afirmar que la sociedad actual está basada en una cultura hipersexualizada. Plutarco da pistas para comprender que a las alturas de los siglos II y III de nuestra era el calor por otros cuerpos era parte de la vida cotidiana, y no todo era aphrodisia y amor del

41 Programas de Afectividad y sexualidad. Décimo año, 25-7. 
más puro, nupcial y sosegado, sino que también había ocasión para la porneia. La inmoralidad ha sido por mucho, un problema de índole filosófico y teológico. Dentro de sus preocupaciones estaba: excesos en la comida, hurtos de los bienes paternos, juegos de dados, banquetes, orgías, amoríos con doncellas y mujeres casadas ${ }^{42}$.

Nada de lo anterior es ajeno a lo que vive hoy la juventud y la sociedad en general, donde más bien el sexo tiene múltiples vías de acceso, aunque no por ello todas gratificantes, reales y saludables. Quedarse en el discurso de la represión y exclusión no posibilita análisis más finos. Si traemos a la discusión el ejemplo de la ideología de Restauración Nacional o la naciente facción de Nueva República, claramente podemos recordar la voz de un Fabricio Alvarado diciendo que a los gays hay que amarlos, que son recibidos con aprecio y cariño dentro de la comunidad, entre otras cosas. El binomio inclusión-exclusión debe superarse, a menudo la relación entre estos dos polos es no solo problemática sino dialéctica.

Más que represión hay múltiples discursos sobre el sexo: literatura barata sobre sexo, mercados de pornografía con una amplia taxonomía de categorías, clubes nocturnos con múltiples opciones, salas clandestinas de masaje,

42 Plutarco, Obras morales y de costumbres I, 16. Traducción de Concepción Morales y José García López, 75. clubes de fiesta y baile donde se puede cultivar el acercamiento sexual, relaciones impropias que desembocan en muertes de mujeres, abusos sexuales por parte de líderes religiosos, como el caso del acusado sacerdote Mauricio Víquez, quien representa una doble moralidad dentro de la moralidad costarricense. Existe una hipersexualización y es ahí, en esas múltiples variantes, donde deben hacerse análisis más finos y críticos. Los mismos líderes religiosos, padres de familia y personas religiosas ligadas a partidos políticos son quienes arremeten en contra de los Programas de Afectividad, pero son vivo ejemplo de esta doble moralidad.

En conclusión, y desde el punto de vista estrictamente teológico podemos inferir que la inspección y el cuidado de sí conforman una paradoja en el marco de estos programas de afectividad, donde la confesión y el silencio todavía están presentes y deben ponderarse, además aparece poco la vinculación genuina entre sexualidad y espiritualidad, lo cual supone un desafío a las personas que son asesoras o maestras de religión. Se concluye que los avances en derechos humanos, el dialogo con las personas discentes, así como la orientación hacia la diversidad sexual y de género, es un aporte significativo para el proceso pedagógico de la sexualidad, y que todo lo que acá se dice es con el afán de construir saberes más amplios y experiencias 
saludables. Los programas de afectividad son asertivos en su apertura a las condiciones de las personas estudiantes partiendo de situaciones reales en las que está presente tanto el placer ${ }^{43}$ como la abstinencia ${ }^{44}$, en el ámbito sano de opciones para la vivencia de lo libidinal. Asimismo, la violencia sexual $^{45}$ es tratada con seriedad, responsabilidad y minuciosidad.

Lo cierto es que, la mirada ya sea teológica, ya sea filosófica, debe ir en la línea de la liberación, la escucha de la polifonía dentro de las personas estudiantes, los cuerpos distintos, que encierran en sí mismos una riqueza y diversidad étnica, cultural, espiritual, así como sexual, que puede teñir de colorido y creatividad el abordaje de estas guías. Ante esto, una cita de Plutarco que llama a la comprensión:

Así pues, ejecutar todos los consejos que hemos dado, es, quizá, una obra irrealizable; pero el tratar de esforzarse por la mayor parte de ellos también es algo que necesita, ciertamente, buena fortuna y mucho cuidado; sin embargo está al alcance de la naturaleza humana ${ }^{46}$.

43 Programa de Estudio de Afectividad y Sexualidad. Tercer ciclo, 55.

44 Programa de Estudio de Afectividad y Sexualidad, 58.

45 Plutarco, Obras Morales y de Costumbres I, 16. Traducción de Concepción Morales y José García López, 61-3.

46 Plutarco, Obras morales y de costumbres I, 1. Traducción de Concepción Morales y José García López, 81.
Así pues, habida cuenta del carácter finito y limitado de la condición humana, el cuidado de sí como acto de habitarse a sí mismo supone un desafío constante, digno y necesario dentro del cual los Programas de Afectividad ofrecen su aporte humanista, pensado y analítico, pero no por ello exento de críticas.

\section{Bibliografía}

Agamben, Giorgio. 2014. Altísima Pobreza. Reglas monásticas y forma de vida. Homo Sacer IV, I. Traducción de Flavia Costa y María Teresa D’Meza. Valencia: Pre-textos.

Aranguren I, G.M Colombas. 2006. La Regla de San Benito. Biblioteca de Autores Cristianos 406. Madrid: BAC.

Brown, Peter. 1993. El cuerpo y la sociedad. Los hombres, las mujeres y la renuncia sexual en el cristianismo primitivo. Traducido por Antonio Juan Desmonts: Barcelona: Muchnik Editores.

Calvo Martínez, Tomás. 2013. Historia de la Filosofía Antigua: Enciclopedia Iberoaméricana de Filosofía. Volumen 14. Edición de Carlos García Gual. Madrid: Trotta.

Clemente de Alejandría. 1998. El Pedagogo. Introducción por Ángel Castiñeira Fernández y traducción y notas por Juan Sariol Díaz. Madrid: Gredos.

Corbin Alain, Courtine Jean-Jacques, Vigarello Georges. 2006. 
Historia del cuerpo. Volumen III. Las mutaciones de la mirada: El siglo XX. Traducción de Alicia Martorell y Mónica Rubio. Madrid: Taurus.

Foucault, Michel. 2019. Historia de la Sexualidad IV. Las confesiones de la carne. Edición establecida por Frédéric Gros, presentación de Edgardo Castro y traducción de Horacio Pons. Madrid: Siglo XXI.

García M., Colombás. 2004. El monacato primitivo. Madrid: BAC.

Le Goff, Jaques y Truong, Nicolas. 2005. Una historia del cuerpo en la Edad Media. Barcelona: Paidos.

La sexualidad y la salud sexual reproductiva de las y los adolescentes con énfasis en prevención de VIH/ Sida. 2005. Módulo de Capacitación para Adolescentes Multiplicadores en Salud, San José, Costa Rica.

Ministerio de Educación Pública, República de Costa Rica. 2017. Programa de Estudio de Afectividad y Sexualidad. Tercer ciclo. San José: MEP.

Ministerio de Educación Pública, República de Costa Rica. 2017. Programa de Estudio de Afectividad y Sexualidad. Décimo año. San José: MEP.

Platón. 2014. El Timeo. Diálogos VI. Filebo, Timeo, Critias. Traducción, introducción y notas por María Ángeles Durán y Francisco Lisi. Madrid: Gredos.
Platón. 2008. Diálogos III. Fedón, Banquete, Fedro. Traducciones, introducciones y notas por C. García Gual, M. Martínez, Hernández, E. Lledó Íñigo. Madrid: Gredos.

Plutarco. 1995. Obras morales y de costumbres, Moralia I. Introducción, traducción y notas de Concepción Morales y José García López. Madrid: Gredos, Biblioteca clásica 78 y 213.

Plutarco. 2003. Obras Morales y de Costumbres. Volumen X. Erótico, Narraciones de amor, Sobre la necesidad de que el filósofo converse con los gobernantes, A un gobernante falto de instrucción, Sobre sí el anciano debe intervenir en política, Consejos políticos, Sobre la monarquía, la democracia y la oligarquía, La inconveniencia de contraer deudas. Vida de los Diez oradores, Comparación de Aristóteles y Menandro. Madrid: Gredos.

San Jerónimo. 1993. Obras Completas. Epístolas I. Edición bilingüe promovida por la orden de San Jerónimo. Introducciones, traducciones y notas por Juan Bautista Valero. Madrid: BAC.

Séneca. 1986. Epístolas Morales a Lucilio I. (Libros I-X, Epístolas 1-80). Introducción, traducción y notas de Ismael Roca Meliá. Madrid: Gredos. 